\title{
Facilitation Directions in Studying Humanities by Medical Students
}

\author{
Tatiana Vladimirovna Smirnova, Elena Vladimirovna Vlasova \\ dept. of Philosophy, Bioethics and Cultural Studies \\ Ural State Medical University, USMU \\ Yekaterinburg, Russia \\ smirtavlad@yandex.ru
}

\begin{abstract}
The article devoted to the problem of the facilitation of studying in higher education. Along with the history of the student-centered approach in teaching, it discusses the need for the formation of a new type of relationship between student and teacher: relations of cooperation and mutual understanding. Individual and personal competences of the teacher are considered, among which the communicative one is important. Particular attention is paid to the description of specific innovative techniques that involve the great number of students as soon as possible. These techniques have been tested by the authors during their own pedagogical experience while working with medical students of the University in the process of teaching courses in philosophy, bioethics and culture, and have established themselves as highly productive.
\end{abstract}

Keywords - Higher education; facilitation; active learning; student-centered learning; game-based learning; express-methods; dialog-based teaching

\section{INTRODUCTION}

The technique of the teaching process facilitation is no longer a novelty for modern Russian education. Its components have been actively discussed and applied in practice since the 1990 's, a period of democratization of education instead of the traditional authoritarian approach

Theoretical foundations of facilitation were laid even earlier, in the 50's, by representatives of the American humanistic psychology, one of the founders of which was Carl R. Rogers, a well-known psychologist and educator. In clinical psychology, he went from the development of client-centered therapy theory to the need for this approach in the field of pedagogy. His book "Freedom to Learn" was widely acknowledged; in that book, he formulated his fundamentals. He wrote that we had "an entirely new situation in education where the goal of education, if we are to survive, is the facilitation of change and learning" [1].

In our country, there were also similar studies in 1960; in particular, a group of scientists headed by D. Elkonin and V. Davidov formulated the concept of the "developmental education". Later, their theory known as Elkonin-Davidov System also gained international fame thanks to its progressive approach [2]. But at that time, any new psychological and pedagogical trends in education evolved "in spite of, rather than thanks to".
Currently, facilitating settings meet the requirements of time, highly competitive and changing conditions; the personcentered, student-centered, subject-subject teaching approach is on everyone's lips now. As C. Rogers wrote (and it's clearly in line with the position of D. Elkonin and V. Davidov): "The only man who is educated is the man who has learned how to adapt and change; the man who has realized that no knowledge is secure, that only the process of seeking knowledge gives a basis for security. Changingness, reliance on process rather than upon static knowledge, is the only thing that makes any sense as a goal for education in the modern world" [1].

However, recent studies show that the traditional approach to training, and lack of pedagogical culture and studentcentered learning are observed not only in our country but also within the European educational system [3]

Therefore, this topic becomes even more important. According to one of general definitions, the facilitator is a participant of the educational process that helps and facilitates the process of development of knowledge, skills and abilities.

Hence, the activities of the teacher are transformed from shaping activities into those facilitating the independent development of the student. Instead of the learning model of the direct instruction type, a challenging model is suggested, when students come to the right conclusions themselves prompted by special teaching methods. However, effective facilitation requires special skills from the teacher, such as self-control and through attention to communication details as well as to the content of the material.

The work of the facilitating teacher is based on humanistically interpreted learning that aims at considering the student as an individual with unique, personality-specific characteristics, with the inner world and meaningful subjective experience, abilities and skills.

The transition from the paternalistic pedagogic model to the interactive, collegial one is important for optimizing and increasing the efficiency and quality of education in general [4]. The role of the teacher is to assist students in their personal selfdevelopment. This is a difficult task, to resolve which the teachers has to activate all of their internal reserves, including professional, psychological and social experience.

The facilitator teacher should also have special personal qualities such as openness, sociability, empathy, charisma and 
sincerity, as his/her activities are related to the maximum peer communication, to achieve which one has to be able to sympathize and empathize in order to effectively set up and determine the right direction for the intellectual activity of students. It is also very important for the teacher to be able to pick up new ideas and think in a logically consistent manner.

Very important in this regard is the personal cultural level of the teacher, which includes discreetness and correctness in communication, tolerance and respect for the individuality, high culture of speech and the ability to creatively combine professional vocabulary with the everyday one, to be able to translate scientific terminology into the language understood by students; also, it is important for the teacher to have a professional manner of communication including respect and attention to each student.

The aim of the facilitator teacher is to provide students with the opportunity to obtain the knowledge themselves rather than to forcefully impose this knowledge. Thus, the knowledge is internalized immediately into personal experience, and it is acquired much easier and much more efficiently. Students immediately perceive the knowledge thus acquired as their own, and not as a strange pile of facts and information that always call for subsequent personal reflection.

Ideally, the role of the facilitators is reduced to setting a problem, defining parameters that will serve as benchmarks and guidance for its resolving, and provide students with the freedom of search and research activities and intra and intergroup cooperation. In other words, the facilitation method encourages students to interact and develop reflective skills and to acquire knowledge that becomes a part of their internal experience at the time of its generation, and therefore, will have a practical application in life.

We consider it appropriate to recall that, historically, one of the most exciting and effective facilitator teachers was the ancient Greek philosopher Socrates, who called his method 'maieutics' - the art of giving birth to the truth, the midwives art. Using this method of the joint search for the truth, parties came from ignorance to knowledge. And that knowledge was born "here and now", in the course of joint logical activity. Even today, the maieutics can be used as a wonderful method of "rousing minds." It is only necessary to observe the rules of Socratic questioning to ensure correct application of this method.

Advanced principles of modern pedagogy are aimed at stimulating the development of self-integrated personality able to find innovative solutions and to generate new ideas and projects. Such attitudes, rather than impose mandatory didactic units, presume the teacher's ability to make his/her subject interesting, to encourage the independent search for information, to engender a desire to learn something new, thereby attracting attention to the subject, demonstrating its importance, its intellectual, socio-cultural and professional value.

These aspects are especially relevant in the training of high school students for their non-core subjects, such as philosophy and cultural studies at the Medical University.

\section{Methodology}

In writing this article, we used the reflective method, the analysis of the results of pedagogical experiment on the use of innovative teaching methods.

We set the following goal: identify the main pedagogical strategies for the efficient operation of a student-centered learning.

\section{RESULTS}

As pointed out by the reflective learning techniques and coaching experts A. Brockbank and I. McGill, facilitation of higher education involves "paying special attention to the quality of relations (quality of relationships) developing between teacher and student" [5]. This approach involves active learning. Active learning is broadly defined in scientific literature as 'any teaching method which gets students actively involved', as opposed to traditional approaches [6].

Positive long-term significance in facilitating the educational process technology is that it can help to achieve a more effective development of the necessary competencies required by modern people. Teachers themselves have to be personally and professionally fit for educational technologies. If teachers were divided into such types as a content-focused teacher' and a learning-focused teacher [7], it is the second type that we deal within this article. It means that, first of all, a teacher needs to change his/her position from a knowledgetransmission view to a learning- view of teaching.

First and foremost, teachers need communicative competence - the ability to establish relationships with others, with the students, the ability to hear each other and to be heard. Another important component of communicative competence is the ability to competently and reasonably express their views at the same time respecting the other opinion, even opposing views, the ability to engage in a constructive dialogue and to reach a compromise.

Thus, we need to develop the communicative competence of the teacher, in the first place, as a meaningful subject of pedagogical activity. To do this, the teacher must have leadership qualities, creativity, empathy and active lifestyle. For instance, following methods appear in the professional portfolio of the high school teacher: introduction of dialog-based teaching instead of monologue-based one; the use of problematic issues that do not have a clear answer, and apply at the same time to various spheres of life; the promotion of any positive result; encouraging of active listening by means of surveys, paraphrase and real-life examples, etc. Besides, communicative competence of the teacher includes the ability to assess both verbal and non-verbal feedbacks from the audience and respond to them.

In other words, using the concepts introduced in the 1920's by Edward Thorndike, the teacher must have the welldeveloped social and emotional intelligence $[8,9,10]$.

The teacher has the power to create a favorable atmosphere of confidence and security.

This means that, first of all, any facilitator teacher must create a safe, open learning environment where the students 
would not be afraid to express their opinions without putting anything at risk: their image, reputation, marks, etc.

In addition, the facilitator teacher is obliged to take into account the personal practical needs of students and be able to incorporate new knowledge, skills and competencies in the existing system of value orientations and skills helping his/her charges to adapt, evolve and address emerging issues of both personal nature or connected with future professional activity. Such an atmosphere will help students to be liberated so that getting required marks would become a second priority for them.

Thus, the teacher has to create an environment in class, so that all those present would feel that they are involved in common important activities, and their outcome will depend on everyone without any exception.

This goal is promoted by a variety of formats actively used in the teaching of the humanities such as a dialogue, a game, joint team activities and questioning.

It is the game as a teaching technique that has a huge facilitating potential. The game gives excellent results in terms of improving the efficiency of learning and engagement/encouraging of students in completely different fields of knowledge [11, 12, 13, 14]. The game gives the students a sense of freedom, the freedom of choice and decision-making, evaluation of the results of their activities. This self-control becomes a key to further self-development. In addition, the game develops an emotional connection between the parties, which facilitates relationships based on empathy and sets an atmosphere of trust and openness. Another advantage of the game is its interdisciplinary nature: the game requires the involvement of the entire body of knowledge and experience of the player that takes part in it as a whole personality.

The main objectives of a high school teacher in this regard are: stimulating intellectual activity of students, facilitating the assimilation of information as well as the creation of conditions for the formation of core competencies. Remember that the desired outcome of learning is mastering of the setting on selfdevelopment and self-actualization, the ability to use the knowledge gained from different areas, and creatively rework the information so that it would become part of inner experience and could be applied in practice, including professional medical, activity, in real life.

Educational technologies are moving away from paternalistic, traditional models of organization of the educational process. The subject-object interaction between teacher and student is replaced with the subject-subject one that is more efficient for the development of basic competences of students.

Therefore, the teacher is required to see the student not just as a learning unit, as a recipient of knowledge, but as a personality with a certain worldview formed by upbringing and secondary education. The degree of maturity of these philosophical systems is a different issue, and they may be modified in the process of learning in high school, but in any case, they will gain depth and validity of personal significance.
Students' days is the period filled with bright impressions and experiences, period of active personal self-development, when the basic principles of self-consciousness are put together and crystallized. Therefore, the teacher as the bearer of knowledge and skills becomes a model from which to retrieve the socio-cultural, spiritual and moral norms.

Given the shortage of time and a large number of students (up to 32 people in the group), facilitating express methods we have created and tested in seminars on philosophy and cultural studies become particularly important. Their main goal is to involve all students in the learning process, to help the understanding of the material within the dialogic teaching.

Below please find options of facilitating express methods that we use in the teaching of the humanities in the Ural State Medical University:

\section{A. A question to a late comer}

When a latecomer asks permission to enter, the team usually has already resolved, or is resolving some issues relating to the topic of the lesson, so the teacher allowing the late coming student to enter says that his/her 'entry pass' will be an answer to a particular question that is now being discussed. For example, "What is intelligence?", "What is the personality?", "What is value?", "What is the social structure of society?", "The system of value orientations?", "Civil society?", "What is duty? ""Conscience? "And so on ...

The situation soon turns into a kind of game (quest), which involves not only the latecomer (latecomers), but also all those present. They either have just found the answer to the question or are still discussing it, and the opinion of the newcomer is demanded. The latecomer joins immediately the team work. In addition, the need to respond questions in person will prevent some students from coming late afterwards.

\section{B. Review}

In some cases, at the beginning of the seminar, it is extremely productive to ask a few key questions relating to the previous session. What is the outcome?

- Firstly, the opportunity to continue the previous topic or link it with the current one.

- Secondly, check the 'survival rate' of knowledge and effectiveness or ineffectiveness of the previous lesson.

- Thirdly, such a retrospective survey, in addition to obtaining information about how adequately and fully the preceding classes were acquired by the students, allows them to earn marks and realize that the more work they put to acquiring the material (writing in notebooks, taking notes of the key points of the topic), the higher reward they will get for their response.

\section{Express poll 'Association for a concept'}

"The philosophy of Ancient China" is a topic most students know very little (if anything at all) about.

An express survey takes 3-5 minutes, gives you a chance to cover students in the group and to identify the extent of their preparedness for seminars, essential or superficial understanding of the topic as well as the degree of acquiring of 
information obtained during the previous sessions. Therefore, it is imperative to hold it twice: at the beginning and at the end of the class.

For example, you may ask students following questions: "What associations does the concept of "Confucianism"/ "Taoism"/"Middle Ages" evoke in your mind?" (In different topics). Name one or two words. Do not repeat someone else's answer."

Such an express survey is almost impossible to evade, but some people are sometimes forced to admit that this or that concept does not evoke any associations at all. After hearing and discussing the reports on the subject, the teacher re-initiates the "circle of associations." In the second approach, as a rule, there is some obvious progress, and 'losers' that did not understand and did not remember anything are already a rare case.

\section{Express game}

An express game can be used as a summing-up of the topic or as an introduction to one. It takes from 3 to 8 minutes and can be carried out, for example, while the speaker is downloading his/her presentation and setting up the equipment.

The teacher divides students in the class into two teams. For example, "nominalists" and "realists", "sensationalists" and "rationalists", "globalists" and "anti-globalists".

The meaning of the game is to bring convincing arguments and reasons to prove that one's position is right. To do this, one must know the meaning of the views of each of these areas, be able to find the strong and weak points of their "own" and the opposite theory and clearly articulate them, and also to find counter-arguments defending their position and answering questions of the opponent.

\section{E. Problem brainstorming through discussion}

To engage students in a discussion on any educational topic, you must first make sure that all participants in the discussion put the same meaning in the basic concepts of the topic and correctly understand the statement of the problem. As one of the variants of facilitating discussion, we distinguish an algorithm of actions of the facilitator teacher.

- The topic must be expressed as problematic as possible - so much so that the answer would not be obvious even for the teacher. It is fun when the teacher him/herself cannot predict the result of the discussion.

- Listen and record as many responses of students as possible on the stated topic (brainstorming). It does not matter if they are not homogenous and not equally valuable, sometimes repeating the same things in different terms.

- It is useful to record the answers on the blackboard (for clarity) and in notebooks. Subsequently, this will help to remember the details, nuances, see the repetitions and "separate the wheat from the chaff."

- It is necessary to organize the brainstorming activities so that all participants in the discussion were listening to each other carefully. In this case, a succession of arguments appears, and "collective intelligence" begins to work.

- The next stage of the discussion can be grouping, dividing the classroom into supporters of similar positions in the like-minded parties. Students are very happy when it turns out that some classmates think the same as they do. It is not necessary to find like-minded people among the audience. It is possible, for example, that the position of student $\mathrm{A}$ is close to the philosophy of R. Descartes, and the position of student B - to the views of I. Kant. By the way, students get very excited when they are aware that their thoughts are similar to the view of the great men, and they become even more motivated to continue the discussion and search for solutions to the problem.

- After analyzing the strong and weak points of arguments of the participants, eliminating obviously incorrect statements, contradictions and repetitions, the teacher leads discussants to required and reasonable conclusions, to the formulation of the overall solution.

- An important rule: the teacher has no right to evade any acute and provocative questions from the students, otherwise, he/she will lose their confidence and authority, and their judgements will not be sincere.

- Summing up, it is useful and productive to acknowledge the contributions and achievements of each student in the discussion and the search for a final decision.

Thus, express methods of teaching have established themselves as one of the most efficient forms of learning and knowledge control in the Ural State Medical University.

\section{F. Necessary condition}

In addition, achieving the goal of understanding the information received in class is promoted by the technique of contextualization, which means active use in the teaching process of various contexts of everyday life in order to facilitate students' understanding of the educational and scientific material, i.e. the use of social and cultural material familiar for students in the process of teaching and explaining.

Thus, contextualization allows for integration of students' personal everyday experience students with academic topics and problems discussed in class in the University $[15,16]$. Therefore, the method of contextualization is very important in higher education, it is necessary in the teaching of any subject, since it includes all life experience of students in the educational process, making it easier for them to assimilate and understand academic material.

\section{CONCLUSIONS}

Finally, we have come to the conclusion that for the effective application of student-centered approach, the following pedagogical goals must be achieved in a consistent and comprehensive manner. The first goal is to facilitate learning through involving students in the process of active learning; the second aim is to encourage critical reflection on researching theoretical challenges of personal and practical 
significance - reflective learning; and the third one is to summarize and systematize students' knowledge.

There is no doubt about the important role of general humanitarian disciplines in the training of future doctors and medical workers $[17,18,19]$. Studies show that lack of humanitarian education in medical schools needs to be overcome, because it leads to negative results affecting the professionalism of future doctors [20]. Indeed, the course of bioethics implants high deontological principles and basic values as necessary moral foundations of medical practice. Along with bioethics, philosophy develops the ability to think critically and reflective, make informed and reasonable decisions and assess soberly any life and professional situations [21]. Cultural studies, in turn, allows the students to get acquainted with the traditions of different cultures and to realize the need for conflict-free communication based on the principles of empathy, respect, autonomy and freedom of other people. It is particularly important for future medical workers in the current multi-cultural environment

Using express methods of teaching allows for more efficient use of academic hours, and, in fact, can be considered as an option of game interactive forms to acquire the educational material and make sure students understand what they are studying.

Facilitation in general, as a set of methods of optimization and efficient alignment of the educational process, also preconditions the effective development of the teacher and the student promoting communication between educational entities. To achieve high results of educational and character building work, the teacher should be open for continuous selfdevelopment and improvement of pedagogical skills.

\section{References}

[1] C. R. Rogers, Freedom to learn for the 80s, Columbus, OH: Charles E. Merrill Publishing Company, 1983, pp .199-217.

[2] R. V. Puentes, C. G. Coelho Cardoso, P. A. Prudente Amorim, and M. V. Musiychuk, "Elkonin-Davidov System: Historical Aspects (1958-2015)", Humanitarian And Pedagogical Research, vol. 2, no. 2, pp. 6-13, 2018. Retrieved from https://cyberleninka.ru/article/v/elkonin-davidov-systemhistorical-aspects-1958-2015.

[3] D. Kilburn and M. Nind, "Wiles Learning as Researchers and Teachers: The Development of a Pedagogical Culture for Social Science Research Methods?" British Journal of Educational Studies, vol. 62, no. 2, pp. 191207, $2014 . \quad$ Retrieved from https://www.tandfonline.com/doi/full/10.1080/00071005.2014.918576?s $\mathrm{rc}=$ recsys\&.

[4] F. Fatkullina, E. Morozkina, and A. Suleimanova, "Modern Higher Education: Problems and Perspectives", Procedia - Social and Behavioral Sciences, vol. 214, pp. 571-577, 2015.

[5] A. Brockbank and I. McGill, "Facilitating reflective learning in higher education". London/England: Society for Research into Higher Education \& Open University Press, 2007.

[6] M. Keyser, "Active learning and cooperative learning: understanding the difference and using both styles effectively", Research Strategies, vol. 17, no. 1, pp. 35-44, 2000. Retrieved from https://www.researchgate.net/publication/222704753 Active learning a nd_cooperative_learning_Understanding_the_difference_and_using_bot h_styles_effectively.

[7] H. Vilppu, I.Södervik, L. Postareff, and M. Murtonen, "The effect of short online pedagogical training on university teachers' interpretations of teaching-learning situations", Instructional Science, vol. 47, no. 6, pp. 679-709, 2019.

[8] N. Dolev and S. Leshem, "Developing emotional intelligence competence among teachers", Teacher Development, vol. 21, no. 1, pp. 21-39, 2017.

[9] R.E. Boyatzis, "Emotional and social intelligence competencies" in Research Companion to Emotion in Organizations, pp. 226-244, USA: Edward Elgar Publishing, 2008.

[10] R. Corcoran, R. Tormey, "Teacher education, emotional competencies and development education", Procedia - Social and Behavioral Sciences, vol. 2, no. 2, pp. 2448-2457, 2010.

[11] R.F. Herrera, M.A. Sanz, L. Montalbán-Domingo, T. García-Segura, and E. Pellicer, "Impact of game-based learning on understanding lean construction principles", Sustainability (Switzerland), vol. 11, no. 19, 5294, 2019. Retrieved from https://www.mdpi.com/2071$1050 / 11 / 19 / 5294$

[12] S. Vanbecelaere, K. Van den Berghe, F. Cornillie, D. Sasanguie, B. Reynvoet, and F. Depaepe, "The effects of two digital educational games on cognitive and non-cognitive math and reading outcomes", Computers and Education, vol. 143, no. 103680, 2020. Retrieved from https://www.sciencedirect.com/science/article/pii/S0360131519302337? via\%3Dihub

[13] F. Grivokostopoulou, K. Kovas, and I. Perikos, "Examining the impact of a gamified entrepreneurship education framework in higher education", Sustainability (Switzerland), vol. 11, no. 20, 5623, October 2019. Retrieved from https://www.mdpi.com/2071-1050/11/20/5623.

[14] O. Ameerbakhsh, S. Maharaj, A. Hussain, and B. McAdam, "A comparison of two methods of using a serious game for teaching marine ecology in a university setting", International Journal of Human Computer Studies, vol. 127, pp. 181-189, July 2019.

[15] E.H. Gebre and J.L. Polman, "From "context" to "active contextualization": Fostering learner agency in contextualizing learning through science news reporting", Learning, Culture and Social Interaction, vol. 24, no. 100374, March 2020.

[16] E. Meites, S. Bein, A. Shafer, "Researching medicine in context: The arts and humanities medical scholars program", Medical Humanities, vol. 29, no. 2, pp. 104-108, December 2003.

[17] X. Yun, J. Guo, and H. Qian, "Preliminary thoughts on research in medical humanities", BioScience Trends, vol. 11, no. 2, pp. 148-151, 2017.

[18] A. Kuper, P. Veinot, J. Leavitt, (...), L. Richardson, and C.R. Whitehead, "Epistemology, culture, justice and power: non-bioscientific knowledge for medical training", Medical Education, vol. 51, no. 2, pp. 158-173, 2017.

[19] Patterson, A. Sharek, D. Hennessy, M. Phillips, M. Schofield, S. "Medical humanities: A closer look at learning", Medical Humanities, vol. 42, no. 2, pp. 115-120, 2016.

[20] S. Morano, A. Lotti, M.M. Canepa, G. Sterrantino, D. Beleva, L. Iannuzzi, S. Downe, "Humanities in the undergraduate medical and midwifery curriculum: A descriptive Italian comparative study", Minerva Ginecologica, vol. 70, no. 6, pp. 700-709, December 2018.

[21] H.-C. Liao and Y.-H. Wang, "The application of heterogeneous cluster grouping to reflective writing for medical humanities literature study to enhance students' empathy, critical thinking, and reflective writing", BMC Medical Education, vol. 16, no. 1, 234, September 2016. 